\title{
Una tumba nazarí de estelas anepigráficas
}

\author{
María José García Larios*
}

\begin{abstract}
RESUMEN
Se restauró en enero de 200I, por la Delegación de Cultura de la Junta de Andalucía en Granada, la Fuente de la Plaza del Carmen de Alhama de Granada. Al levantar la fuente nos encontramos dos piezas de piedra calcarenita a $1 \mathrm{~m}$ de profundidad la mayor $\mathrm{y}$ a I,60 ms, la menor, separadas unos 2 metros entre sí. Como voy a exponer, tengo datos suficientes para pensar que es un importante hallazgo, correspondiente a los dos testigos de una tumba de época nazarí. Son dos estelas funerarias hispanomusulmanas de carácter anepigráfico, de época nazarí, concretamente del siglo XIV correspondientes a enterramientos de gente de cierto relieve social. Han sido restauradas y se encuentran depositadas en el Museo Arqueológico de Granada para su protección, conservación y difusión.
\end{abstract}

PALABRAS CLAVE: Tumba nazarí, estelas anepigráficas, Alhama, conocer, proteger, conservar, difundir.

\section{INVESTIGACIÓN HISTÓRICA}

Es innegable el pasado árabe de Alhama que tuvo una gran importancia desde el punto de vista económico y comercial en la época nazarí por su estratégica localización. Era una ciudad- fortaleza. Según Luis de Montes ', estaba cercada por espesa y altísima muralla, flanqueada de trecho en trecho por sólidas torres y robustos bastiones. Este hecho lo confirma

\begin{abstract}
In January 200I the fountain located in the Plaza del Carmen in the town of Alhama de Granada (Grana$\mathrm{da}$, Andalusia) underwent restoration work conducted by the local office of the Department of Culture of the Regional Government of Andalucía. When the fountain was raised, two calcarenite stones were uncovered. The larger stone was buried I meter deep and the smaller one 1.6 meters, lying about 2 meters from each other. There is sufficient evidence to suggest that this is an important archaeological discovery and that they are funerary markers belonging to a tomb of the Nazari period. These Hispano-Islamic tombstones probably date from the 14th century and belong to persons of high social rank. The stelae have been restored and are currently deposited at the Archaeological Museum of Granada for display and conservation.
\end{abstract}

KEY WORDS: nazari tomb, anepigraphic stelae, Alhama, know, protect, preserve, disseminate.

también Ibn Battuta, historiador y viajero musulmán. Nos dice $\mathrm{Madoz}^{2}$ que la muralla estaba al Norte y Oeste y tenía un castillo que ocupaba todo el lado occidental de la población, cuyo acceso se realizaba a través de dos puertas, la de Málaga y la de Granada que se hallaban en las extremidades que unían las murallas con el tajo. Alhama poseía mezquita. El nombre de Al-hama, según comenta Ibn Battuta, viene de tener dos manantiales de los que

\footnotetext{
* Conservadora del Patrimonio Artístico de la Delegación de Cultura de la Junta de Andalucía en Granada.

I Luis Montes "Toma de Granada".
} 
salían dos chorros de agua y sobre ellos existían dos edificios del SXIII, de los que en la actualidad quedan algunos restos y que servían para tomar el baño por separado los hombres y las mujeres. Fue conquistada en 1482 por los Reyes Católicos.

Hay un grabado de Hoefnagle de 1564 , acompañado de descripción, en el que se puede ver cómo estaba la ciudad fortificada en ese momento. Cerca de la Plaza del Carmen se ubicaba el castillo.

El castillo en 1849, según W. G. Clark, apenas se diferenciaba ya de las casas que lo rodeaban. En el SXVIII, Ponz ${ }^{3}$ nos dice que Alhama tenía un acueducto árabe con arcos. Tras el terremoto de 1884 y que afectó enormemente a la ciudad, hubo bastantes edificios destruidos y otros se recuperaron.

En la actualidad quedaban como testimonios del momento árabe, el lienzo de muralla de la Cl. Adarve Remedios, restos de dos torreones que comunicaban con la ciudad, uno en el cortijo de Torresolana y los cimientos de otro, encima de lo que queda de los baños. Así mismo hay una galería subterránea que sale al río y de la que se conserva la mitad inferior (se utilizó en su momento para escapar de la ciudad). Otros elementos musulmanes son el Cobertizo de la Calle Llana y algunas calles sin salida al lado y en la calle Zapateros de trazado árabe.

Cuando la Delegación de Cultura de Granada restauró la Fuente de la Plaza del Carmen de Alhama en enero de 200 I, al levantar la fuente y sondear el terreno nos encontramos dos piezas de piedra calcarenita a I $\mathrm{m}$ de profundidad la mayor y a 1,60 ms, la menor, separadas unos 2 metros entre sí. Son el objeto de la presente investigación.

\section{ANÁLISIS MATERIAL Y TÉCNICO}

Las piezas son de calcarenita, piedra franca de la cantera de Santa Pudia.

La pieza más pequeña lleva en ambos lados, centrando la composición, un arco angrelado de herradura muy cerrado y rehundido. Va almenada la faja superior. No lleva epigrafía. Tiene $38 \mathrm{cms}$ de largo por $30 \mathrm{cms}$ de ancho y $10 \mathrm{cms}$ de grueso. El radio del arco sería de unos $3 \mathrm{cms}$, ya que el alto del mismo es de 6,3 y el ancho de $6 \mathrm{cms}$. La prolongación o jambas del arco es de 3,5 cms de alto. Es el testigo de la cabecera.

La pieza mayor lleva en ambos lados o caras, dos arcos gemelos de herradura angrelados, muy cerrados e igualmente rehundidos. También va almenada la faja superior. No lleva epigrafía. Tiene $49 \mathrm{cms}$ de largo por $38 \mathrm{cms}$ de ancho y $8 \mathrm{cms}$ de grueso. El radio de los arcos sería de $2 \mathrm{cms}$ aproximadamente, ya que el alto de éstos es de 4,5 y el ancho de $4 \mathrm{cms}$. Posee unas fuertes impostas de 1,5 cms de alto y las jambas o prolongación del arco, son de 4,6 cms. Sería el testigo de los pies, según vamos a ver.

A ambas piezas les falta el extremo inferior, es de suponer que eran un poco más largas pues se enterraba la estela en un tercio de su altura. Según Torres Balbás ${ }^{4}$, las medidas usuales de las estelas funerarias hispanomusulmanas eran de 38 a $58 \mathrm{cms}$ de largo y como éstas, 8 a 10 cms de grosor. Por su parte, Carlos Vilchez ${ }^{5}$, basándose en la afirmación que hace Bourrilly y Laoust (respecto a señalamientos del Norte de Africa que son casi iguales a los hispanomusulmanes, la cabecera es cúspide única y los pies bífida), a su vez afirma prácticamente, que las lápidas decoradas con un arco pertenecen a la cabecera y con dos a los pies, como ocurre con dos lápidas del Museo

\footnotetext{
2 Madoz, Pascual. Diccionario Geográfico-estadístico-histórico de España y sus posesiones de Ultramar, I845-I 850. Granada.

3 Ponz. "Viaje de España" I776. Madrid, por D. Joaquín Ibarra.

4 Torres Balbás, Leopoldo. “Las ciudades hispano-musulmanas”,Edit. Instituto Hispano Árabe de Cultura. 1985.

5 Vilchez Vilchez, Carlos. "Cementerios Hispanomusulmanes granadinos”, pags 66 a 70. Universidad Granada. 1986.
} 
de la Alhambra, número de registro 3.677 y 3.678. Esta coincidencia - dice Vilchez - entre los señalamientos españoles y los magrebíes, se debe a la relación existente entre los ámbitos culturales nazarí y meriní.

Los cementerios musulmanes de Al - Andalus, siguiendo la tradición romana, se extendían fuera de los muros de la ciudad, sin vallado alguno, junto a los caminos que conducían a las puertas principales de la cerca. "Además de estos cementerios, había varios pequeños intramuros, unos y otros alejados del núcleo urbano: todo alcázar regio solía tener su rawda, o sea, su panteón (sepultura rica) casi siempre junto a un jardín" 6 . La Alhambra lo tuvo entre los siglos XIV y XV.

Respecto a las tumbas, debido a la austeridad religiosa y el sentido igualitario del Islam, en las necrópolis de Al- Andalus, no había ostentosidad, propias de la vanidad póstuma de otras religiones. Aunque los ricos se enterraban en panteones y los pobres tenían una piedra tosca, sin labrar, en la cabecera de la tumba. Nos dice Balbás ${ }^{7}$ que si las personas eran de algún relieve social y económico, las tumbas se señalaban por varias formas, una de ellas era con dos estelas a modo de gruesas losas de piedra o mármol, hincadas verticalmente y orientadas hacia la Meca o qibla, a la cabecera la mayor y una más pequeña a los pies, a modo de "testigos" que limitaban la sepultura. Unos bordillos de piedra con la misma decoración, más cortitos, bordeaban el rectángulo de la sepultura. La simbología de la tumba era una cama, con su cabecera y sus pies. Llevaban epigrafía y este campo solía estar recuadrado por el fondo rehundido.

A partir del siglo XIl, comienzan a adornarse las estelas en sus frontales por un arco ciego, decorativo, de poco relieve, que en algunos casos era la representación simbólica de un mihrab. Algunas estelas tenían friso de almenillas sobre su faja superior. La inscripción fúnebre se desarrollaba en el fondo del arco y en la faja rectangular situada entre él y la parte horizontal del alfíz.

Las dos estelas que estudiamos no llevan epigrafía, por lo que se podrían englobar dentro de las anepigráficas ${ }^{8}$. De época nazarí se han hallado estelas de diversos materiales, destacando el mármol, el barro cocido y la piedra. La mayoría de señalamientos encontrados en época nazarí son de piedra. En Granada la piedra era arenisca de la Malá y Gabia, de la cantera Montevives. Aunque el arco angrelado de herradura se observa ya en el momento almohade, se continúa y afianza en el nazarí, además, los arcos nazaríes tienen características almohades sobre todo al principio. El no tener material cerámico adyacente y que parezcan piezas de acarreo, hace que no se puedan aportar más datos que los expuestos en estas páginas.

Hemos comprobado en el Museo de la Alhambra, que existe en la Sala VI una estela nazarí de características muy similares a la mayor hallada en Alhama, con dos arcos gemelos, incluso nos parecen mejor labrados los que presentamos aparte de ir angrelados. La estela del Museo coincide con el registro 3.678 ya mencionado y perteneció a la muralla de la Alcazaba de la Alhambra, lo que nos confirma la importancia del hallazgo y el momento.

Muy similar a la estela pequeña de un arco hallada en Alhama, es la existente en el mismo Museo con el número de registro $\quad$ 1.467, lleva un arco de herradura tambien cerrado y polilobulado por 9 lóbulos, aunque no llega al angrelamiento del nuestro (formado por múltiples lóbulos pequeños), ésta registrada, es de época de Muhammad V (|354- |39|) por poseer, según Vilchez ${ }^{9}$, una prolongación de un tercio

6 Torres Balbas, L. Ibidem.

7 lbidem.

8 Vilchez Vilchez, Carlos. "Lápidas Anepigráficas".

9 Vilchez Vilchez, Carlos "Lápidas Anepigráficas" 
del radio del arco de herradura decorativo, según comparación hecha con el capitel del Museo de la Alhambra número de registro 3. 916. La nuestra como hemos visto es de poco más de la mitad del radio de su arco, con lo que sería algo posterior sino de la misma época.

Las estelas hispanomusulmanas, además de encontrarse en su lugar de origen, el cementerio, han sido reutilizadas para hacer construcciones posteriores. Así en la Puerta de la Justicia y en la Acequia Real se han encontrado a modo de sillares. Al sanear la solería del Patio de los Leones, se encontraron lápidas tabulares con textos epigráficos picados, las leyendas iban enmarcadas por cenefa que remataba en arco de herradura generalmente polilobulado, cuya tradición se remonta al siglo XII como hemos dicho. Hay lápidas reutilizadas en la construcción de la parroquia de San Miguel y algunas en el Convento de Santa Isabel la Real, que pueden ser del antiguo cementerio de la Alcazaba Qadima.

Se depositaron en el Museo Arqueológico en su momento, por la Comisión de Monumentos algunas lápidas, provenientes de derribos. Gómez Moreno y Gallego Burín también donaron. Aparecieron lápidas al derribar el Cobertizo de Tovar que unía la Casa del Gran Capitán y en otra casa de la calle Cocheras. En el 1967, al construir la casa de la parroquia de San Pedro, apareció un grupo en el huerto. De aquí pasaron al antiguo Museo Hispanomusulmán y actual Museo de la Alhambra.

La Fuente de la Plaza del Carmen o Pila de la Carrera (debajo se encontraron las dos estelas funerarias), estaba situada anteriormente en el Paseo. El Paseo forma parte de las transformaciones de Alhama de la primera mitad del XIX. En 1836 se iniciaron las obras del Paseo, situado frente al Castillo. La fuente se vino abajo en el terremoto de 1884 y aunque se repuso, se trasladó a su actual emplazamiento hace aproximadamente 40 años. Han podido utilizarse como material de relleno piedras de todo tipo. Este espacio cerca del castillo, bien podía ser donde se ubicara un antiguo cementerio musulmán y donde se han encontrado las estelas, el lugar de enterramiento. Aunque hay más probabilidad de que hayan servido, como parece, de material de relleno y procedieran posiblemente de un inmueble o muro derribado durante el terremoto y en el que habrían sido reutilizadas, como hemos expuesto antes, en otros casos. En el lugar donde se encontraron no observaron ningún otro elemento relativo o relacionado con este hallazgo.

Cuando descubrimos las estelas, precisaban un tratamiento preventivo pues habían cambiado su microclima habitual y necesitaban limpieza y consolidación. Por tanto, se depositaron en el Museo Arqueológico Provincial para su protección, conservación y difusión que es lo que pretendemos. Con esto se cierra el ciclo necesario para cualquier actuación en el patrimonio, conocer para proteger, proteger para conservar y difundir. La tutela de un bien cultural ha de encontrar su presupuesto en la existencia de un acto inicial de "accertamento". Conforme a los postulados de la Comisión Franceschini, consideramos que todo acto administrativo debe estar precedido y determinado por un acto cognoscitivo sobre el objeto que se pretende proteger, añadiendo como Alberto Clementi, que además debe ir seguido por un acto cognoscitivo. La difusión es un requisito imprescindible para la conservación de nuestro patrimonio, ya que sólo se protege lo que se conoce y comprende y es por tanto el medio más eficaz para su defensa, asi lo reconocen leyes y foros de debate, así viene recogido en el Plan General de Bienes Culturales y en la Ley del Patrimonio Histórico de Andalucía.

\section{CONSERVACIÓN DE LAS PIEZAS Y ESTUDIO DE LOS FACTORES DE DETERIORO}

La piedra es una calcarenita, piedra franca de la cantera de Santa Pudia, material muy poroso y permeable, de escasa densidad y resistencia, fácil de labrar pero que resiste poco el deterioro, la filtración de agua, tanto por capilaridad (agua del subsuelo) como la de lluvia. La infiltración de agua en la calcarenita es una de las causas más comunes de deterioro. Este agua ataca y disuelve el escaso material de unión dando lugar a la pérdida de cohesión 
interna y posterior arenización. Se cristalizan sales en el interior de la roca (subeflorecencias), que terminan originando esfuerzos internos que aceleran el deterioro de la roca.

Las estelas funerarias tenían zonas arenizadas a nivel superficial, así como faltas de soporte, por falta de cohesión. No obstante, según la empresa restauradora Siglos ${ }^{10}$, el núcleo del soporte pétreo tenía buena resistencia mecánica y presentaba un mejor estado de conservación que la superficie. Las eflorescencias no eran abundantes en las piezas, pero podían observarse subeflorescencias en las áreas más arenizadas y descarnadas. Aunque no se conoce la naturaleza de las sales, supone que la mayoría de ellas han sido aportadas por la tierra circundante unida a la humedad. Había concreciones duras de tierra y sales en general por toda la superficie, aunque eran más gruesas en zonas concretas.

Es preciso señalar la agresión de carácter antropogénico, ya que ambas piezas presentaban huellas de herramientas producidas recientemente (lo que ha provocado faltas de soporte), originadas posiblemente durante las labores de sondeo del terreno para el levantamiento de la fuente y en el proceso de su extracción.

\section{TRATAMIENTO REALIZADO}

Las intervenciones, realizadas por la empresa restauradora SigloS, han ido encaminadas a mantener la obra sin añadir ningún tratamiento o elemento que pudiera modificar, alterar o distorsionar físicamente la estabilidad de la obra.

La limpieza se ha efectuado primero con cepillos de cerda blanda para pasar a una limpieza puntual más exhaustiva, retirando las costras duras que persistían con ayuda de escalpelos y bisturís. Aún así, había zonas resistentes en las que se actuó de manera mecánica sin dañar el sustrato pétreo, por lo que se realizó una limpieza química puntual con papeta sin que afectara a la pátina de la piedra. Por último, para eliminar las posibles sales solubles que pudieran quedar en el interior se aplicó un baño por inmersión en agua desmineralizada.

El tratamiento de reintegración con mortero se debió a la necesidad de realizarlo en las zonas deterioradas para unificar estéticamente el conjunto. Sólo se han reintegrado las faltas de soporte de las piezas en su parte inferior, para permitir su exposición en posición vertical, así como las faltas de las huellas producidas por herramientas en su proceso de extracción. El resto de faltas de soporte son de pequeñas dimensiones y denotan el desgaste y paso del tiempo, por lo que no entorpecen su visión, y por tanto no han sido reintegradas.

El mortero de restauración utilizado en la obra lo ha fabricado específicamente Siglos para las necesidades de la calcarenita, con una elevada porosidad que permite la evaporación del agua que pueda infiltrarse en el interior $y$ una resistencia mecánica inferior a ésta, lo que garantiza su degradación preferente respecto a la piedra original El mortero lo han hecho a base de cal hidráulica y árido de calcarenita y para el color, se han realizado diversas pruebas hasta obtener un tono similar a las piezas originales. Los pigmentos son inorgánicos.

Con la consolidación se pretende mejorar la cohesión interna del material, la adhesión entre las partes dañadas y aquellas no alteradas. Para la consolidación de las obras se ha utilizado un Silicato de etilo con Siloxano (ESTEL I I00), permeable al vapor de agua que deja inalterado el aspecto exterior de la piedra evitando formaciones de manchas o películas brillantes y amarilleo bajo la acción de los rayos U.V.

Se trata de un compuesto orgánico a base de silicio formado por moléculas ya polimerizadas. Por tanto, no se verifica una polimeriza-

I0 SigloS, Conservación y Restauración. Memoria de la Restauración de las Estelas Funerarias. Museo Arqueológico Provincial de Granada. 
ción ulterior en el interior del material pétreo, lo cual constituye una ventaja ya que no es necesario controlar las condiciones de humedad relativa. Este producto además de consolidar proporciona características hidrófugas al compuesto, es reversible, mejora las características mecánicas y reduce la porosidad del material.

Se ha aplicado por inmersión, "para garantizar que toda la estructura porosa sea bañada. El consolidante se ha aplicado en la concentración que se comercializa hasta la saturación del material. De este modo, la resina ha ido penetrando por capilaridad hasta el núcleo de la piedra, y esto permite distribuir la resina de forma gradual en el interior de la piedra, de forma que las cantidades de materia activa disminuyen a medida que aumenta la profundidad. Así no se crean discontinuidades en las propiedades mecánicas del material tratado, y las partes más superficiales se consolidan de forma más enérgica" "I.

\section{AGRADECIMIENTOS}

A Carlos Vilchez Vîchez, Director del Museo Arqueológico de Granada, especialmente, por su inestimable ayuda en los datos aportados.
A SigloS, Taller de Restauración, integrado por las restauradoras Lourdes Blanca López, Julia Ramos Molina y Ma Dolores Blanca López, que han facilitado las fotografías y la Memoria de la Restauración de la que se han extraido los datos de intervención.

\section{BIBLIOGRAFÍA}

Madoz, Pascual: Diccionario Geográfico-estadístico-histórico de España y sus posesiones de Ultramar, 1845 - 1850. Granada.

Montes, Luis: Toma de Granada.

Ponz: Viaje de España, 1776. Madrid, por D. Joaquín Ibarra.

SigloS, Conservación y Restauración: Memoria de la Restauración de las Estelas Funerarias. Museo Arqueológico Provincial de Granada.

Torres Balbás, Leopoldo: Ciudades Hispanomusulmanas. Edit. Instituto Hispano Árabe de Cultura. 1985.

Vilchez Vilchez, Carlos: Cementerios hispanomusulmanes granadinos, Memoria de Licenciatura. Departamento de Arte. Universidad de Granada, 1986.

Vilchez Vilchez, Carlos: Lápidas Anepigráficas, Granada.

\footnotetext{
II SigloS, Conservación y Restauración. Memoria de la Restauración de las Estelas Funerarias. Museo Arqueológico Provincial de Granada.
} 


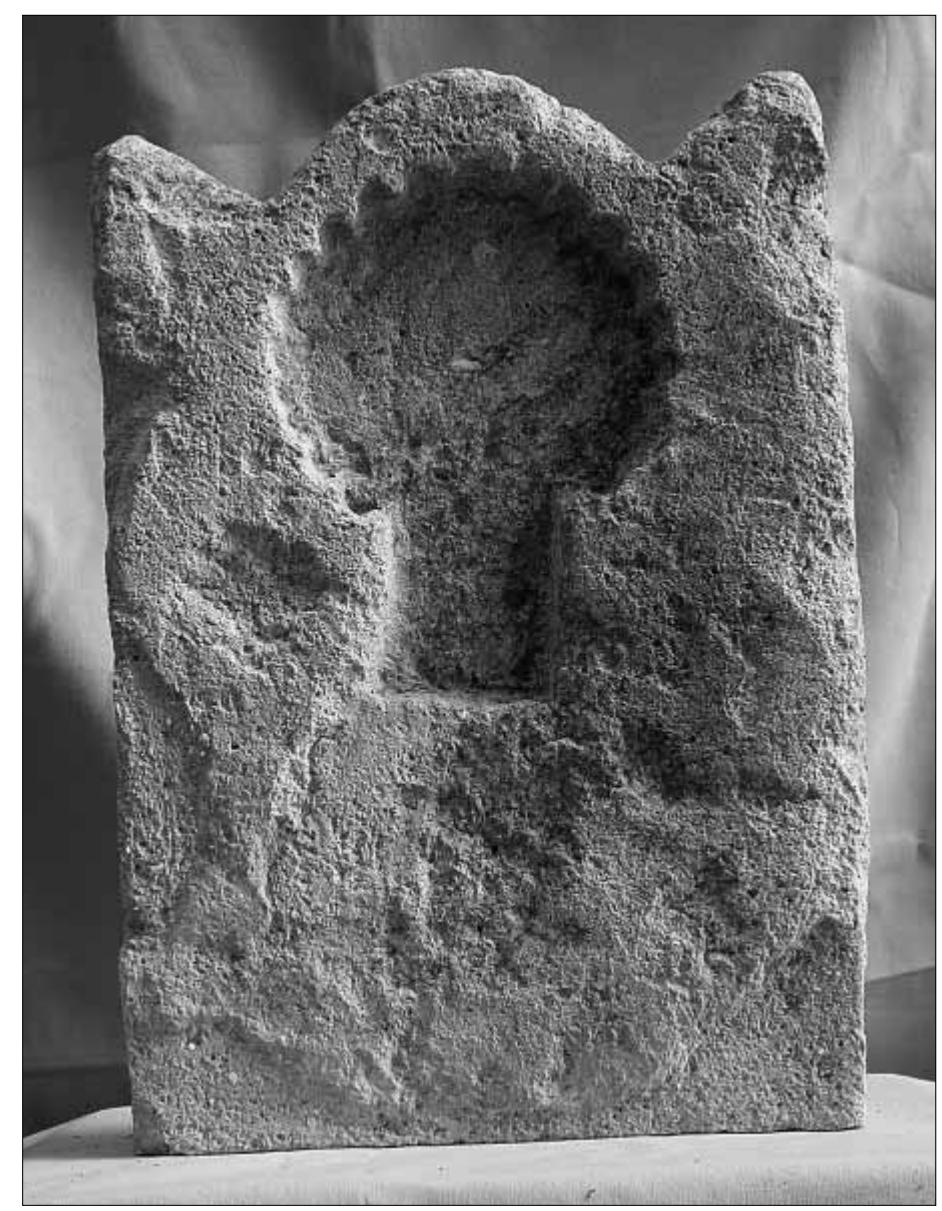

Lam. I. Estela anepigráfica nazari

testigo de la cabecera de un arco

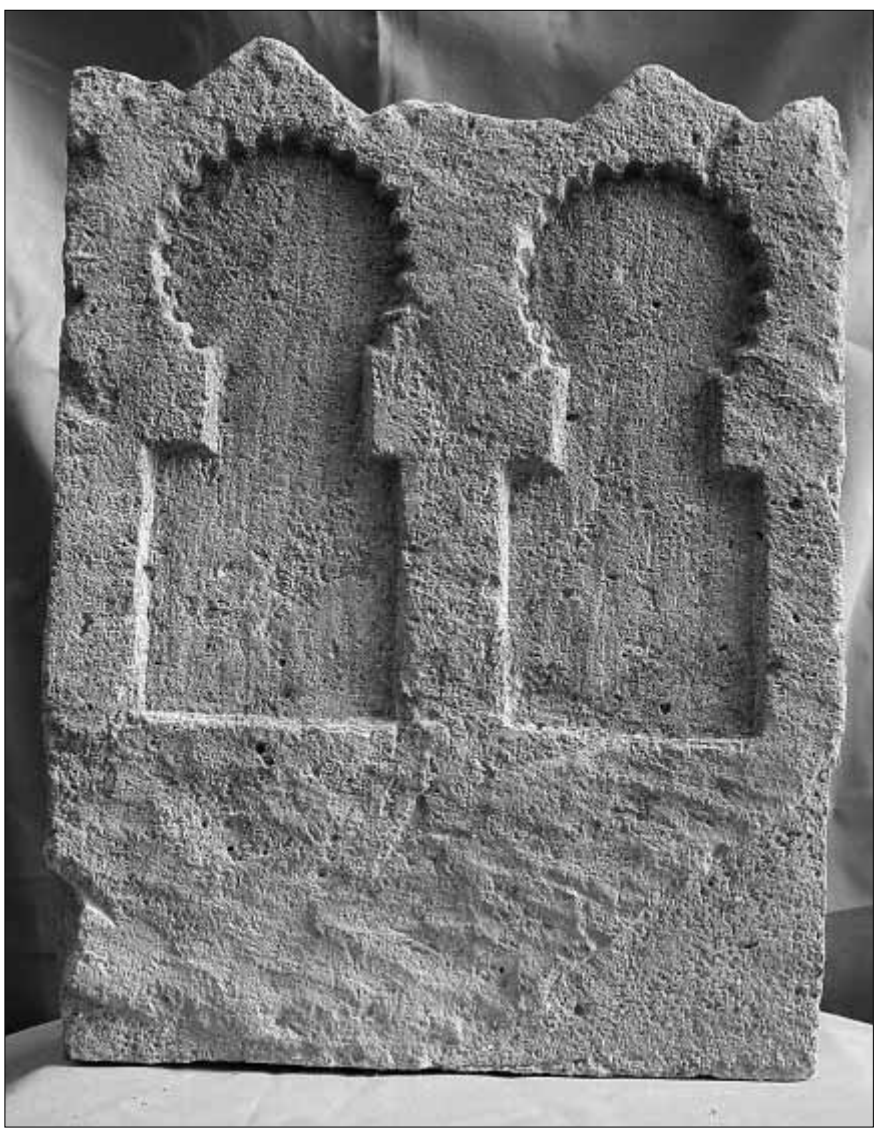


Lam. 3. Estela testigo de la cabecera cara A antes de restaurar
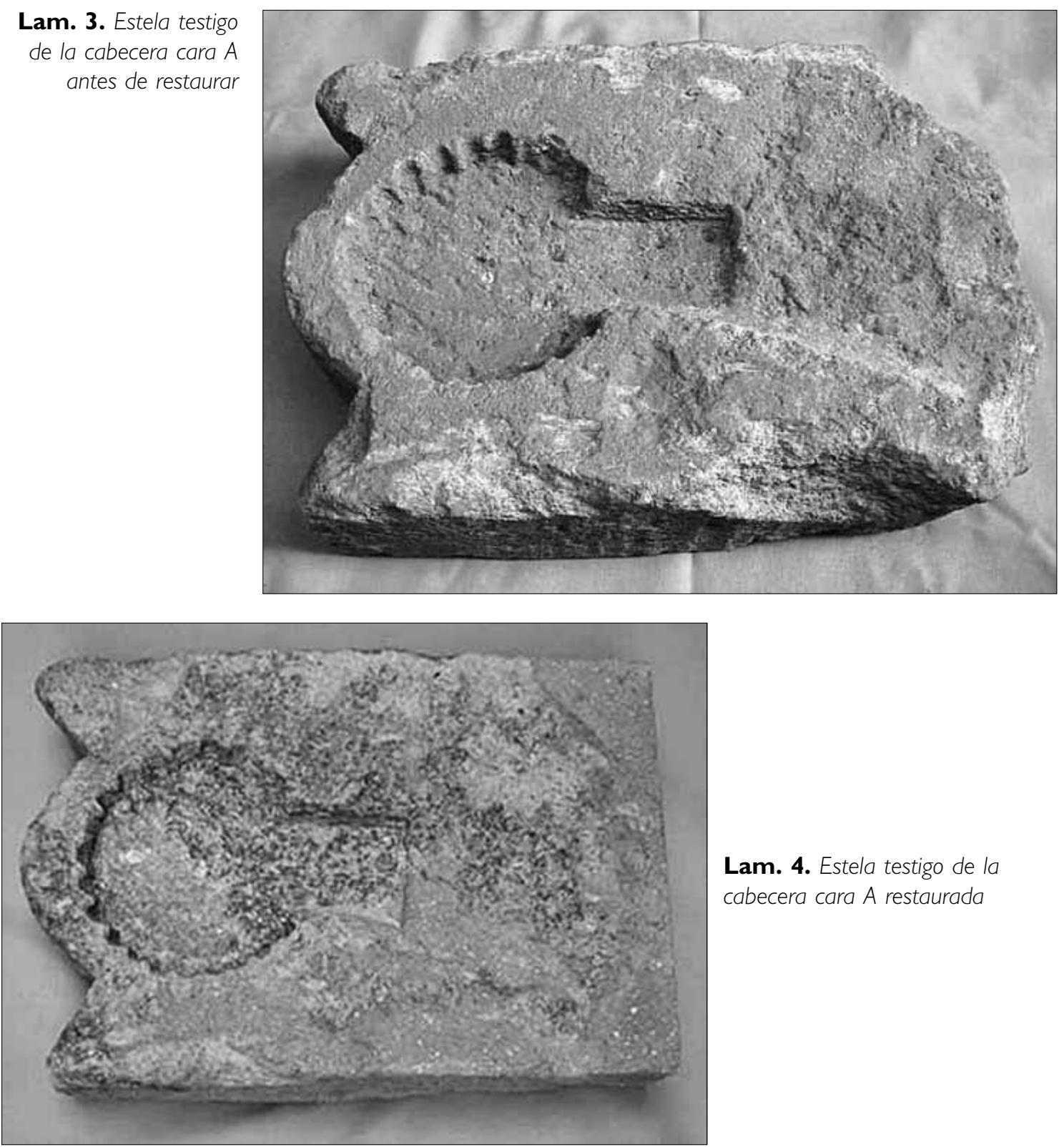

Lam. 4. Estela testigo de la

cabecera cara A restaurada

Lam. 5. Estela testigo de la cabecera cara $B$ antes de intervenir

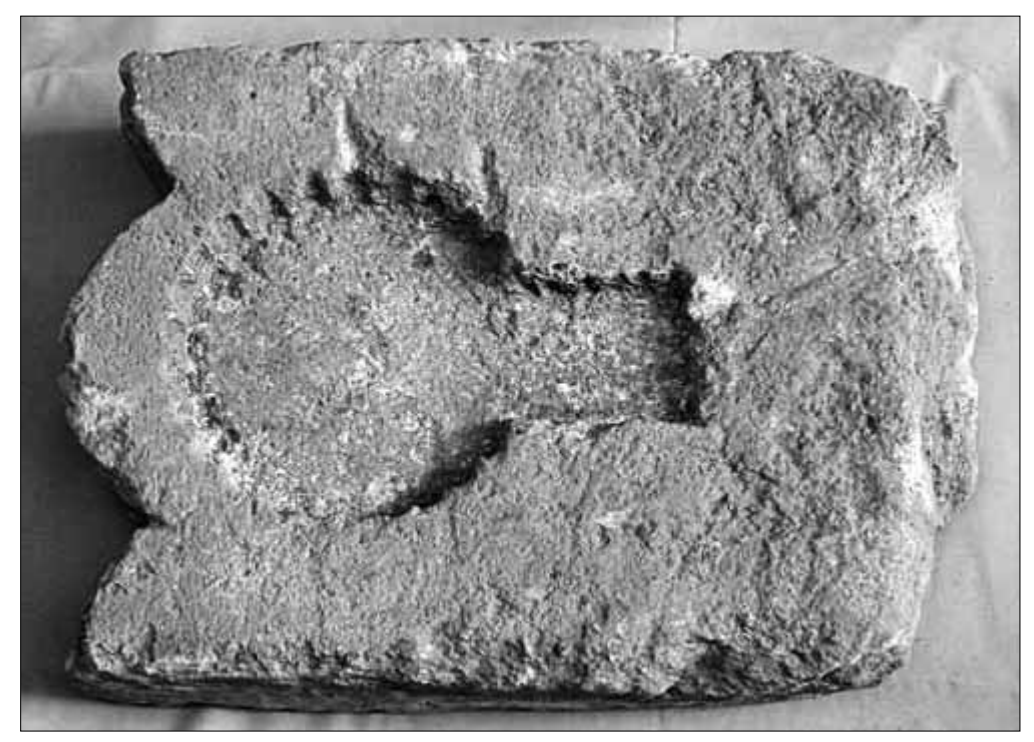




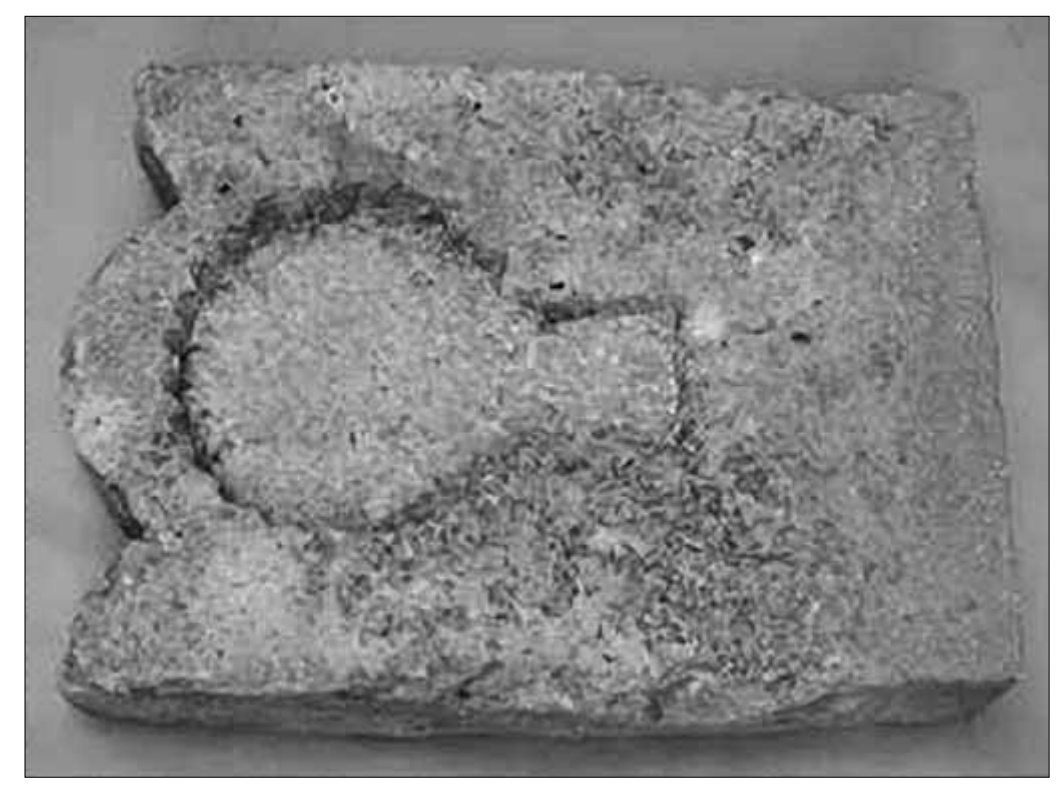

Lam. 6. Estela testigo de la cabecera cara B restaurada

Lam. 7. Estela testigo de los pies cara A antes de restaurar
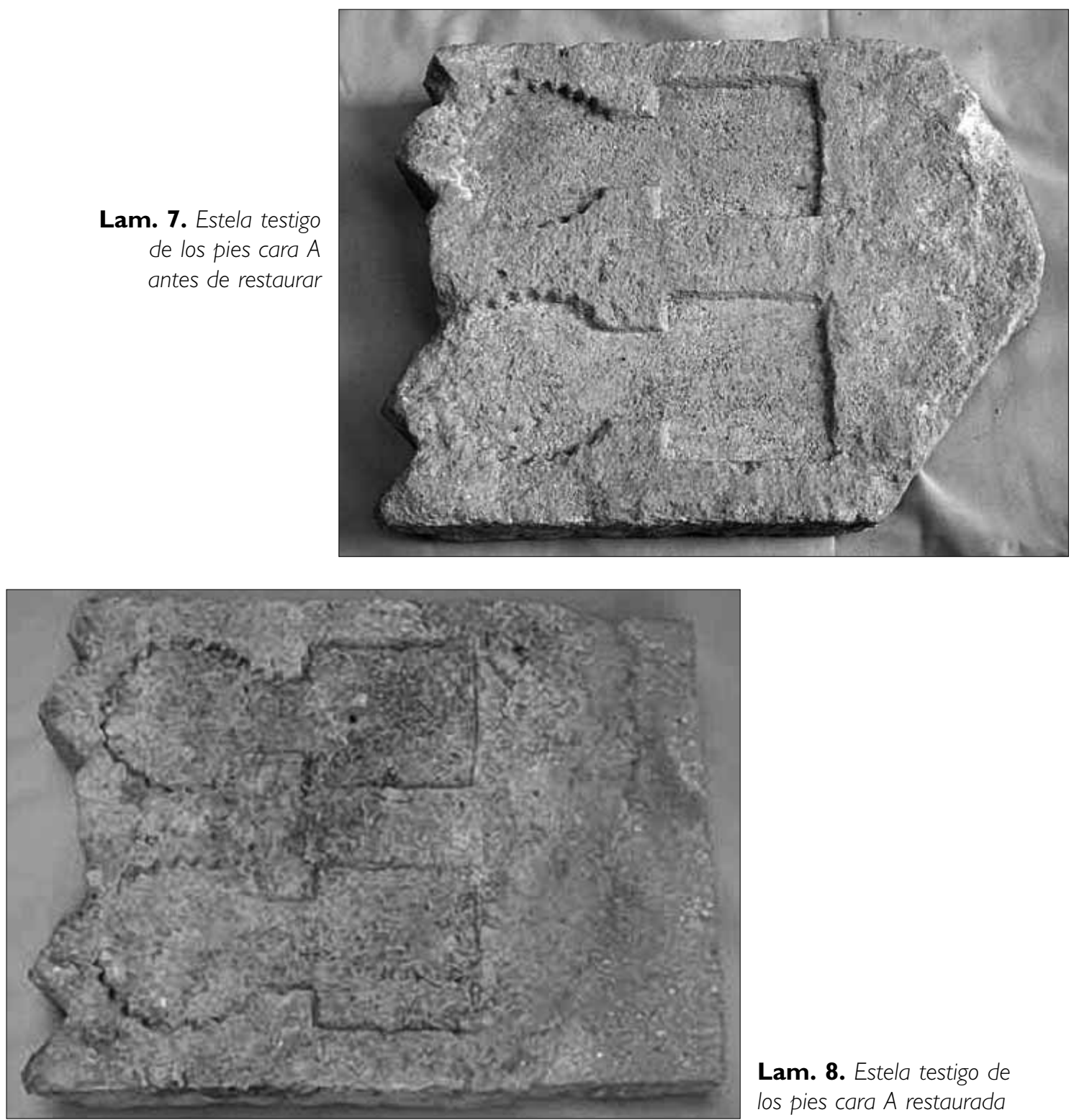

Lam. 8. Estela testigo de los pies cara A restaurada 


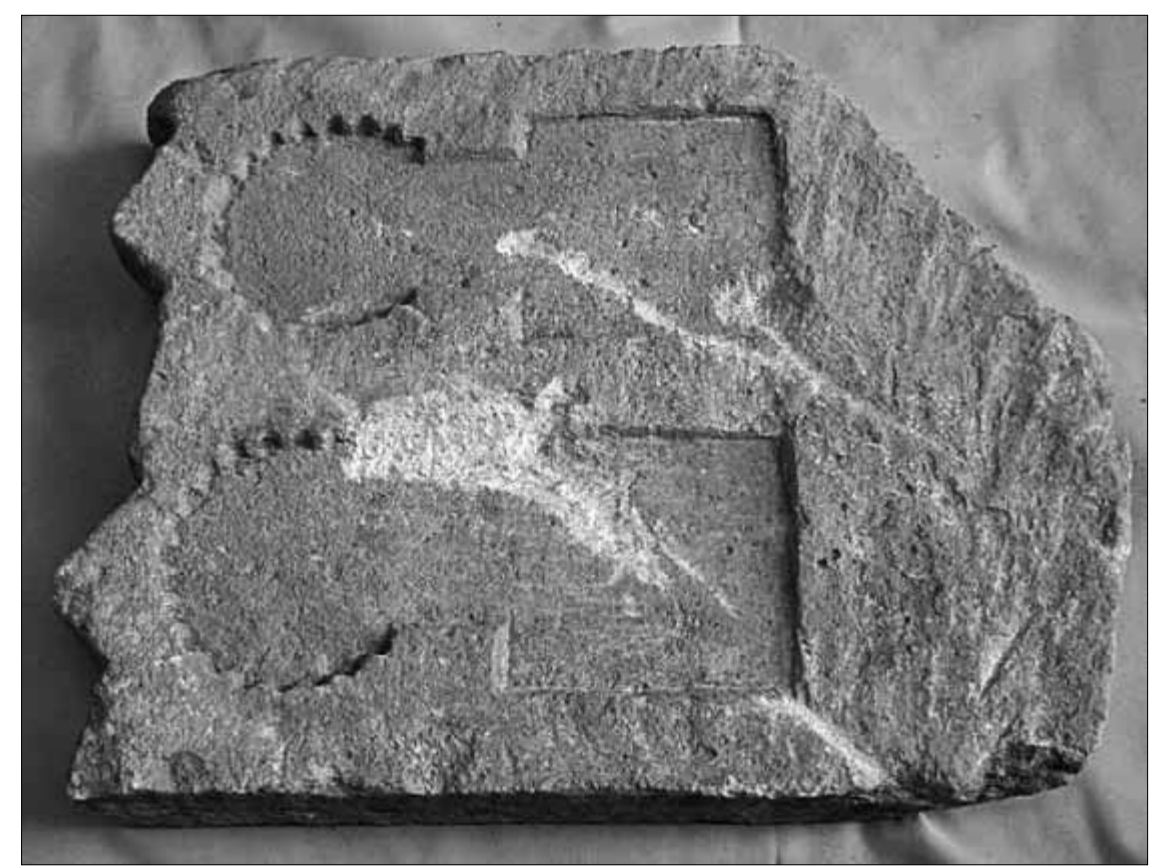

Lam. 9. Estela testigo de los pies cara B antes de restaurar

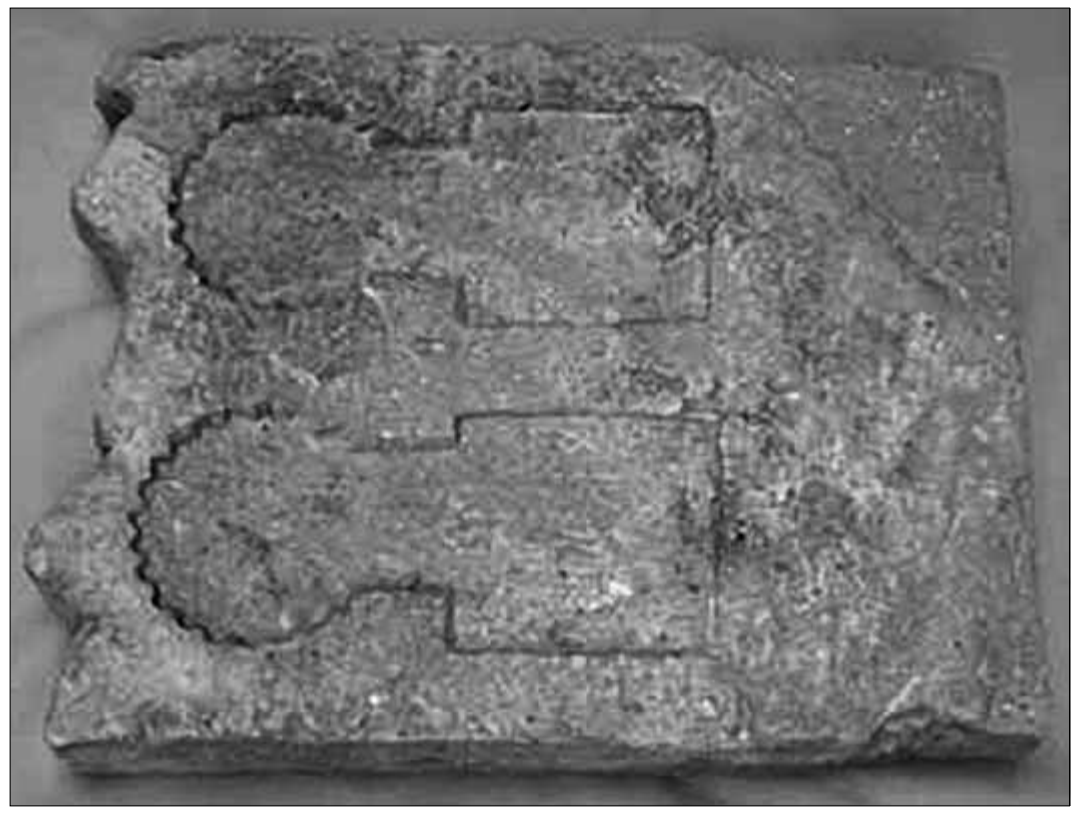

Lam. 10. Estela testigo de los pies cara B restaurada 


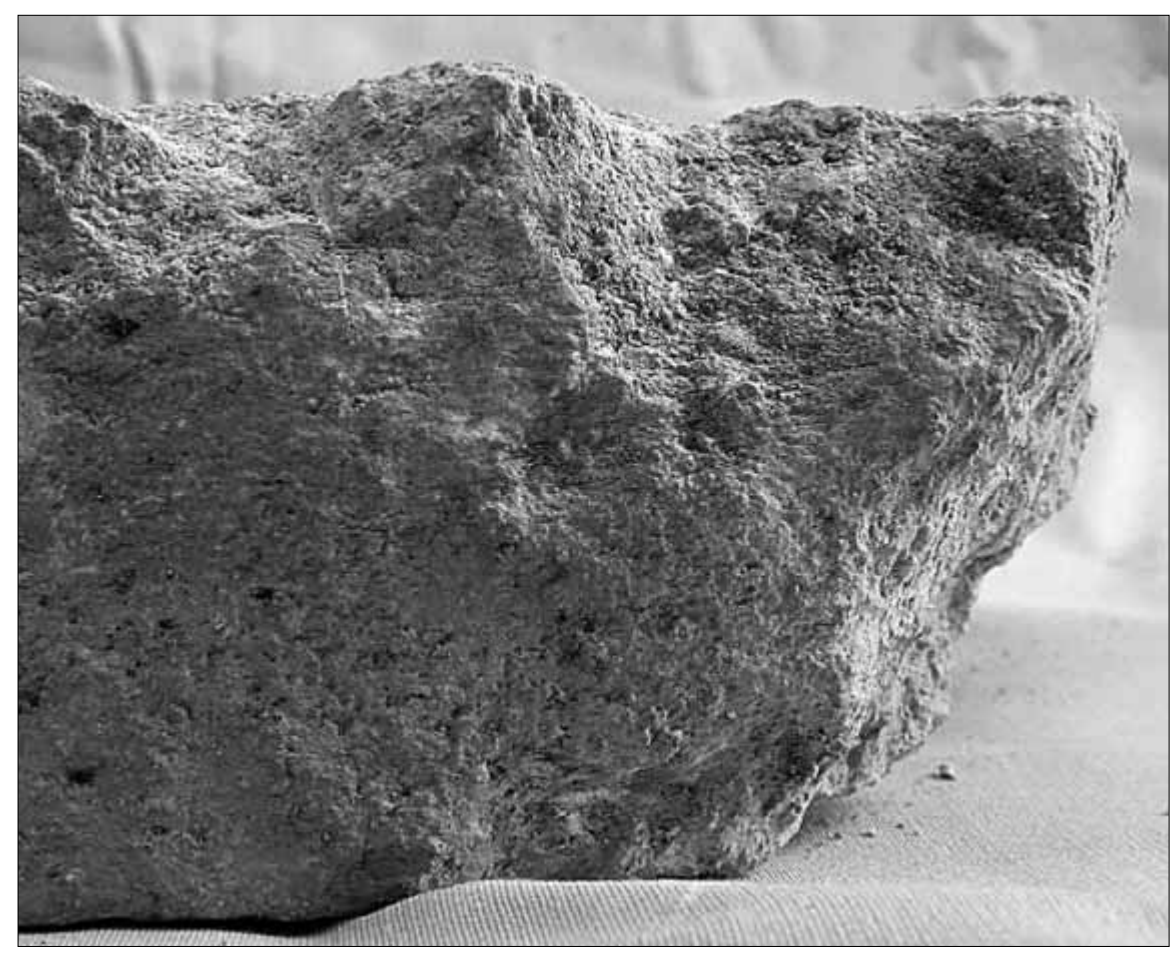

Lam. I I. Detalle del estado de conservación del testigo de los pies

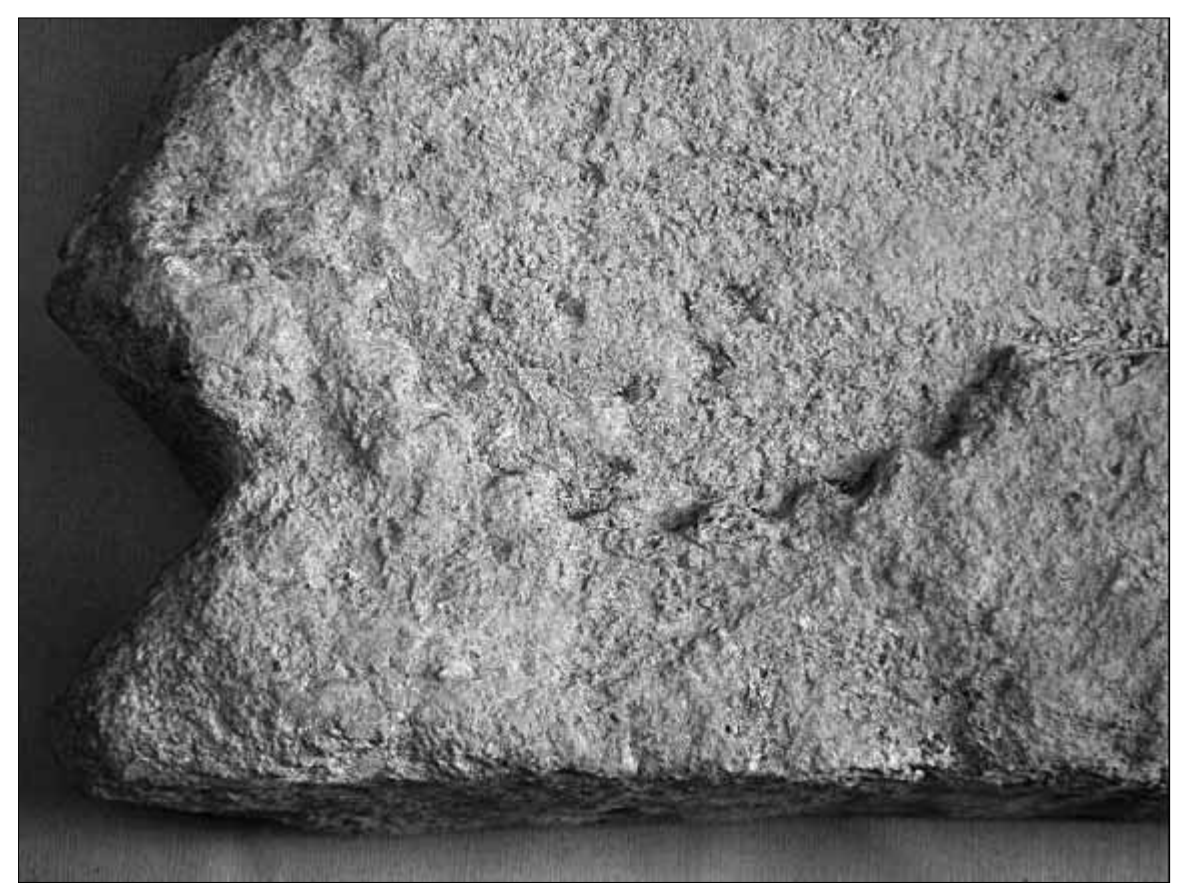

Lam. I2. Detalle de la superficie donde hay concreciones de tierra 